ENGINEERING SCIENCE II 
Macmillan Technician Series

P. Astley, Engineering Drawing and Design II

P. J. Avard and J. Cross, Workshop Processes and Materials I

G. D. Bishop, Electronics II

G. D. Bishop, Electronics III

John Elliott, Building Science and Materials II/III

J. Ellis and N. Riches, Safety and Laboratory Practice

P. R. Lancaster and D. Mitchell, Mechanical Science III

R. Lewis, Physical Science I

Noel M. Morris, Electrical Principles II

Noel M. Morris, Electrical Principles III 


\title{
Engineering Science II
}

\author{
D. E. Hewitt \\ C. Eng., M. I. Mech. E., \\ Lecturer in Mechanical Engineering \\ Department of Mechanical and Production Engineering, \\ Loughborough Technical College
}


All rights reserved. No part of this publication may be reproduced or transmitted, in any form or by any means, without permission.

First published 1978 by

THE MACMILLAN PRESS LTD

London and Basingstoke

Associated companies in Delhi Dublin

Hong Kong Johannesburg Lagos Melbourne

New York Singapore and Tokyo

Typeset in 10/12 Times

\section{British Library Cataloguing in Publication Data}

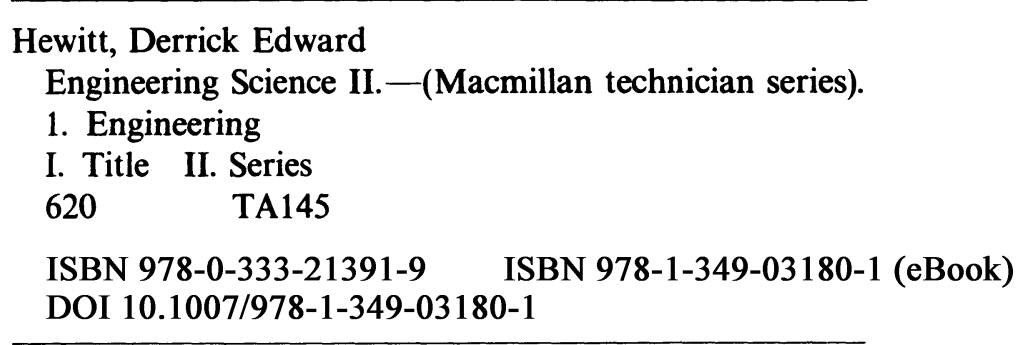

This book is sold subject to the standard conditions of the Net Book Agreement.

The paperback edition of this book is sold subject to the condition that it shall not, by way of trade or otherwise, be lent, resold, hired out, or otherwise circulated without the publisher's prior consent in any form of binding or cover other than that in which it is published and without a similar condition including this condition being imposed on the subsequent purchaser. 


\section{Contents}

Foreword

Preface

\section{Statics-Materials}

1.1 Stress

1.2 Strain

1.3 Hooke's Law and the Modulus of Elasticity

1.4 Elasticity and Plasticity

1.5 The Tensile Test

1.6 Properties of Materials and Stress-Strain Curves

1.7 Introduction to Plastics Materials

1.8 Shear Stress and Shear Strain-Modulus of Rigidity

1.9 Factor of Safety and Working Stresses

Exercises

\section{Statics-Structures}

2.1 Force as a Vector

2.2 Equilibrium-The Triangle and Polygon of Forces

2.3 Bow's Notation

2.4 Conditions of Equilibrium

2.5 The Turning Effect of a Force

2.6 Beam Reactions

2.7 Resultant Forces in Frameworks

2.8 Graphical Determination of Forces in Simply Supported Frameworks Subject to Vertical Loads

2.9 Graphical Determination of Forces in Simply Supported Frameworks Subject to Vertical and Non-vertical Loads

2.10 Graphical Determination of Forces in Cantilever Frameworks

\section{Exercises}

3. Dry Sliding Friction

3.1 The Nature of Dry Sliding Friction ix

$\mathrm{xi}$

1

1

2

3

5

6

11

12

13

14

16

18

18

20

21

22

24

25

26

27

28

30

31

39

39

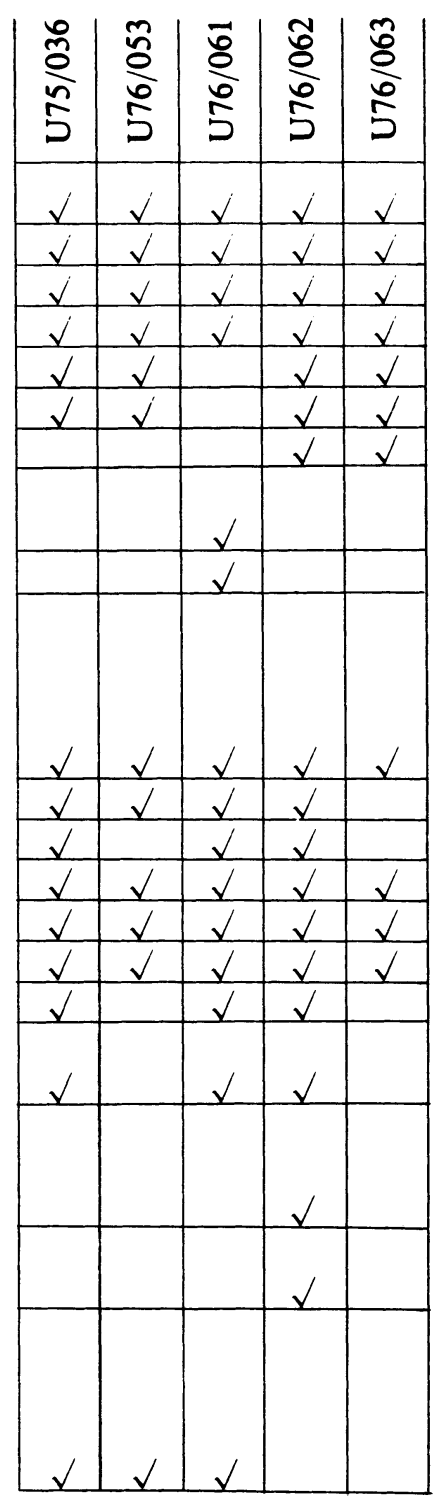


3.2 Angle of Friction (Angle of Repose)

3.3 Full-film and Boundary Lubrication

3.4 Friction Losses in Bearings

Exercises

\section{Simple Machines}

4.1 Simple Machines and Levers

4.2 Mechanical Advantage and Velocity or Distance Ratio

4.3 Velocity Ratio or Distance Ratio of Simple Machines

4.4 Mechanical Efficiency of Simple Machines

4.5 Limiting Efficiency - the Law of a Simple Machine

4.6 Overhauling in a Simple Machine-Ideal Machines

Exercises

\section{Velocity}

5.1 Constant-velocity and Uniformly Accelerated Motion

5.2 Distance-Time, Velocity-Time and AccelerationTime Graphs for Uniformly Accelerated Motion

5.3 Uniformly Accelerated Motion Due to Gravity

5.4 Velocity as a Vector

5.5 Relative Velocity Applied to Mechanisms

5.6 Circular Motion and Angular Velocity

Exercises

\section{Dynamics - Newton's Laws of Motion}

6.1 Newton's First Law of Motion

6.2 Newton's Second Law of Motion

6.3 Newton's Third Law of Motion

6.4 Forces Required to Produce and Maintain Motion Exercises

\section{Dynamics - Work and Energy}

7.1 Work and Energy
42

43

44

46

48

48

49

50

55

57

59

61

62

62

64

66

67

69

70

73

76

76

77

79

79

83

84

84

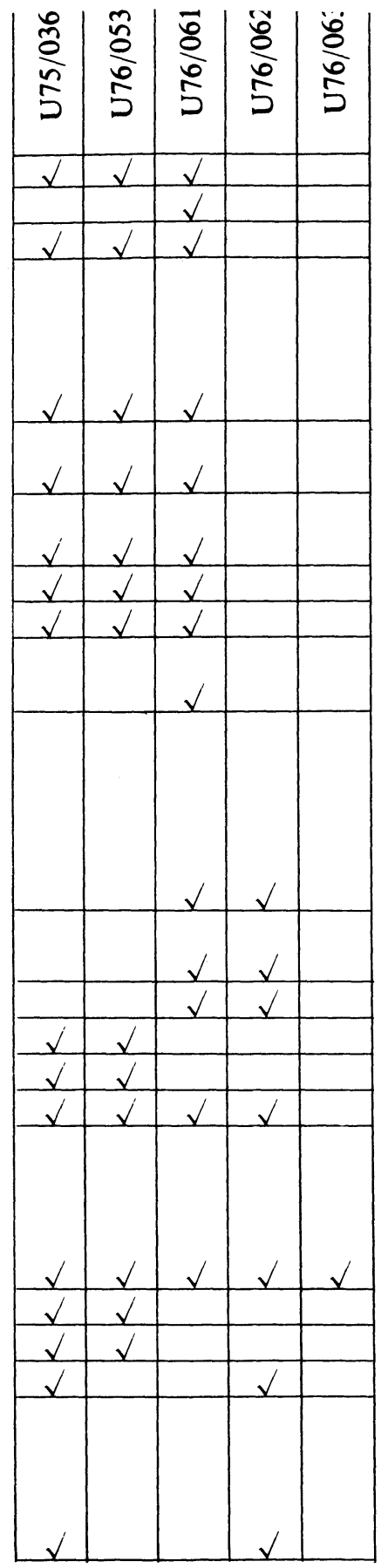


7.2 Work done by a Constant Force

7.3 Work done by a Varying Force

7.4 Work done by an Inclined Force

7.5 Mechanical Energy

7.6 Potential Energy

7.7 Kinetic Energy

7.8 Conservation of Energy

7.9 Power - the Rate of Doing Work Exercises

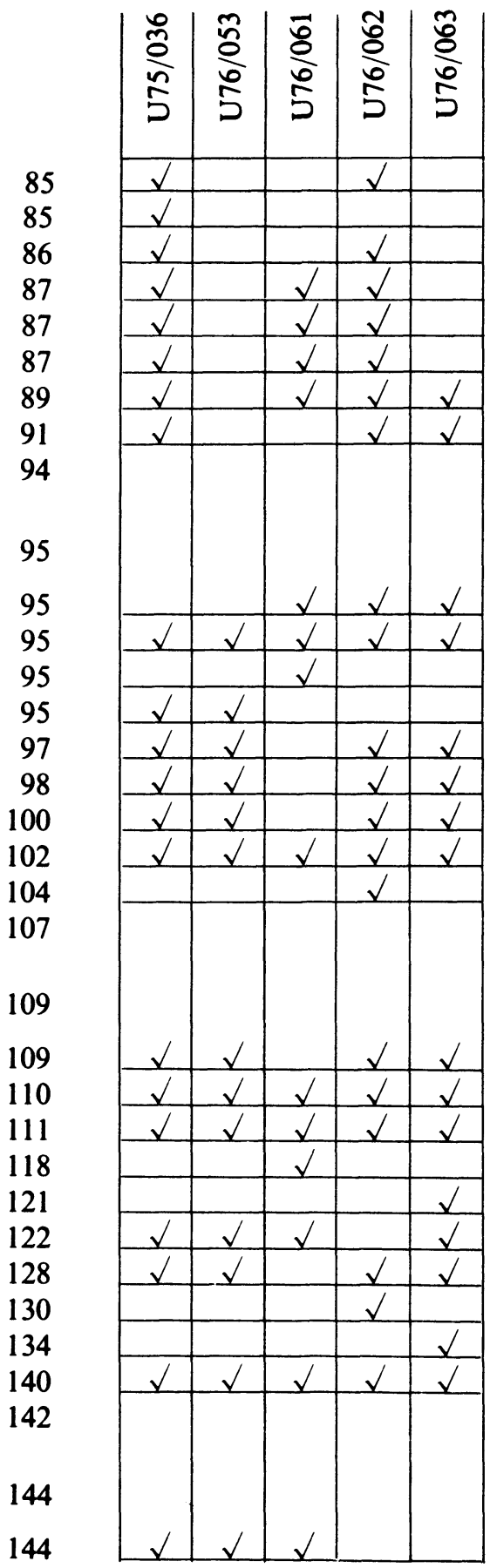

8. Heat and Its Applications

8.1 Heat and Energy

8.2 Effects of Heat

8.3 Sources of Heat

8.4 Heat Transfer

8.5 Temperature

8.6 Calorimetry

8.7 Change of State

8.8 Change of Size

8.9 Properties of Gases

Exercises

9. Electricity and Electrical Measurement

9.1 The Nature of Electric Charge

9.2 The Electric Current

9.3 The Electrical Circuit

9.4 Factors Determining Resistance

9.5 Electric Power

9.6 Electrical Measurements

9.7 Measurement in A.C. Systems

9.8 Electrostatics

9.9 Electrochemistry

9.10 Safety Precautions for Electrical Equipment Exercises

\section{Magnetism and Electromagnetism}

10.1 Evidence of a Magnetic Effect 
10.2 Shape and Distribution of Magnetic Fields

10.3 The Concept of Magnetic Flux and Field Strength

10.4 The Direct-current Motor

10.5 Electromagnetic Induction

10.6 Machines for Generating Electric Current

10.7 Flux Change as an Alternative to Flux Cutting

10.8 Self-inductance and Mutual Inductance

10.9 Production of Magnetism in Magnetic Materials

Exercises
145

147

151

155

158

160

163

165

168

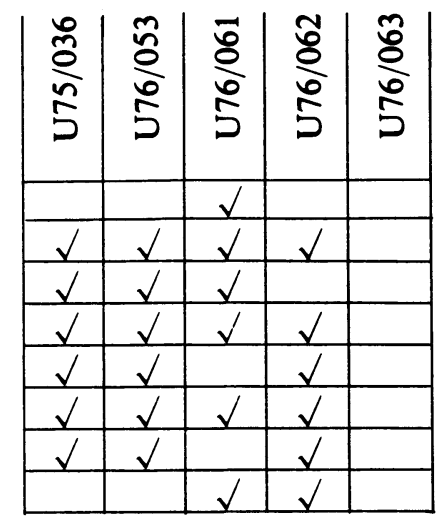




\section{Foreword}

This book is written for one of the many technician courses now being run at technical colleges in accordance with the requirements of the Technician Education Council (TEC). This Council was established in March 1973 as a result of the recommendation of the Government's Haslegrave Committee on Technical Courses and Examinations, which reported in 1969. TEC's functions were to rationalise existing technician courses, including the City and Guilds of London Institute (C.G.L.I.) Technician courses and the Ordinary and Higher National Certificate courses (O.N.C. and H.N.C.), and provide a system of technical education which satisfied the requirements of 'industry' and 'students' but that could be operated economically and efficiently.

Four qualifications are awarded by TEC, namely the Certificate, Higher Certificate, Diploma and Higher Diploma. The Certificate award is comparable with the O.N.C. or with the third year of the C.G.L.I. Technician course, whereas the Higher Certificate is comparable with the H.N.C. or the C.G.L.I. Part III Certificate. The Diploma is comparable with the O.N.D. in Engineering or Technology, the Higher Diploma with the H.N.D. Students study on a part-time or block-release basis for the Certificate and Higher Certificate, whereas the Diploma courses are intended for full-time study. Evening study is possible but not recommended by TEC. The Certificate course consists of fifteen Units and is intended to be studied over a period of three years by students, mainly straight from school, who have three or more C.S.E. Grade III passes or equivalent in appropriate subjects such as mathematics, English and science. The Higher Certificate course consists of a further ten Units, for two years of part-time study, the total time allocation being 900 hours of study for the Certificate and 600 hours for the Higher Certificate. The Diploma requires about 2000 hours of

study over two years, the Higher Diploma a further 1500 hours of study for a further two years.

Each student is entered on to a Programme of study on entry to the course; this programme leads to the award of a Technician Certificate, the title of which reflects the area of engineering or science chosen by the student, such as the Telecommunications Certificate or the Mechanical Engineering Certificate. TEC have created three main Sectors of responsibility

Sector A responsible for General, Electrical and Mechanical Engineering

Sector B responsible for Building, Mining and Construction Engineering

Sector C responsible for the Sciences, Agriculture, Catering, Graphics and Textiles.

Each Sector is divided into Programme committees, which are responsible for the specialist subjects or programmes, such as A1 for General Engineering, A2 for Electronics and Telecommunications Engineering, A3 for Electrical Engineering, etc. Colleges have considerable control over the content of their intended programmes, since they can choose the Units for their programmes to suit the requirements of local industry, college resources or student needs. These Units can be written entirely by the college, thereafter called a college-devised Unit, or can be supplied as a Standard Unit by one of the Programme committees of TEC. Assessment of every Unit is carried out by the college and a pass in one Unit depends on the attainment gained by the student in his coursework, laboratory work and an end-of-Unit test. TEC moderate college assessment plans and their validation; external assessment by TEC will be introduced at a later stage.

The three-year Certificate course consists of fifteen Units at three Levels: I, II and III, with five Units normally studied per year. A typical programme might be as follows.

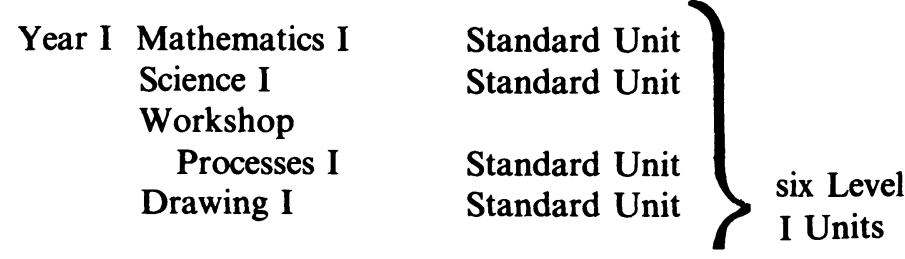


General and

Communications I College Unit

Year II Engineering Systems I

Mathematics II

Science II

Technology II

General and

Communi-

cations II

Year III Industrial

Studies II

Engineering

Systems II

Mathematics

Science III

Technology

III

College Unit

Standard Unit Standard Unit Standard Unit

College Unit

six Level

II Units

College Unit

College Unit

Standard Unit

Standard Unit

College Unit

three Level

III Units

Entry to each Level I or Level II Unit will carry a prerequisite qualification such as C.S.E. Grade III for Level I or O-level for Level II; certain Craft qualifications will allow students to enter Level II direct, one or two Level I Units being studied as 'trailing' Units in the first year. The study of five Units in one college year results in the allocation of about two hours per week per Unit, and since more subjects are often to be studied than for the comparable City and Guilds course, the treatment of many subjects is more general, with greater emphasis on an understanding of subject topics rather than their application. Every syllabus to every Unit is far more detailed than the comparable O.N.C. or C.G.L.I. syllabus, presentation in Learning Objective form being requested by TEC. For this reason a syllabus, such as that followed by this book, might at first sight seem very long, but analysis of the syllabus will show that 'in-depth' treatment is not necessary-objectives such as '... states Ohm's law ... ' or '... lists the different types of telephone receiver ... ' clearly do not require an understanding of the derivation of the Ohm's law equation or the operation of several telephone receivers.

The treatment of each topic is carried to the depth suggested by TEC and in a similar way the length of the Unit (sixty hours of study for a full Unit), prerequisite qualifications, credits for alternative qualifications and aims of the Unit have been taken into account by the author. 


\section{Preface}

The aim of this book is concisely to cover sufficient engineering science material at Level II to meet the needs of any student following a Technician Education Council programme of studies within the fields of Sector A1- General Engineering and Sector A5-Mechanical and Production Engineering.

The standard Units provided by TEC to meet the needs of the outline programmes in these areas are

TEC U76/053 Engineering Science-aiming to give a basic mechanical and electrical engineering science background for engineering manufacturing technology; taken by all students in the mechanical and production engineering field.

TEC U76/061 Engineering Science (1) II-a half Unit aiming to provide a basic background of engineering science for all technician students in the general engineering field.

TEC U76/062 Engineering Science (2) A II-an additional half Unit to develop the engineering science background of the more analytical student following a Certificate programme in general engineering.

TEC U76/063 Engineering Science (2)B II-an additional half Unit to complement TEC U76/061 to give the more practical student following a Certificate programme in general engineering an engineering science background to his technology subjects.

The students taking these particular Units will include those just entering their further education studies, having obtained an $\mathrm{O}$ level G.C.E. pass (Grade 3 or better) in physics or a suitable science, or, alternatively, having obtained a C.S.E. Grade 1 pass in similar subjects.

Other students will include those whose school-leaving attainments are less than those outlined above, but who have successfully

studied TEC Units TEC U75/004 Physical Science I or TEC U76/004 Engineering Science I. There will also be students transferring to a technician course having distinguished themselves on a craft course.

The material within the book is presented in logically arranged chapters, each preceded by its own general objective. Each chapter is sub-divided into concise sections, which any student may select to study to fulfil the specific objectives associated with his programme. Each sub-section is cross-referenced to the particular TEC Unit or half Unit to which it is relevant. Each chapter concludes with specific objectives and these, coupled with the student exercises, should help the student to monitor his own progress effectively and ensure that the specific objectives have been achieved.

There are numerous worked examples within the text, carefully graded in complexity, illustrating where possible the application of the principles involved to everyday and common engineering situations.

The text also includes brief biographical details of some of the scientists and engineers to whom we owe much of our current knowledge. Comment has also been included to emphasise the aspects of science and technology which have particular social and environmental implications. It is hoped that this will assist in the integration of general studies by providing introductory material for discussion on topics such as the history of technology, energy sources, pollution, etc., and will broaden the interests of the student and make him aware of the importance of the engineering industry in society and, in particular, the role of the 'technician' within the industry.

I wish to acknowledge the assistance and collaboration of my colleague, C. H. Salsbury, B.Sc., C.Eng., M.I. Gas E., M.Inst.F., in the preparation of the book, in particular for reading through the manuscript and making helpful comments, and for his contribution of chapters 8,9 and 10 on heat, electricity and magnetism.

D. E. Hewitt 